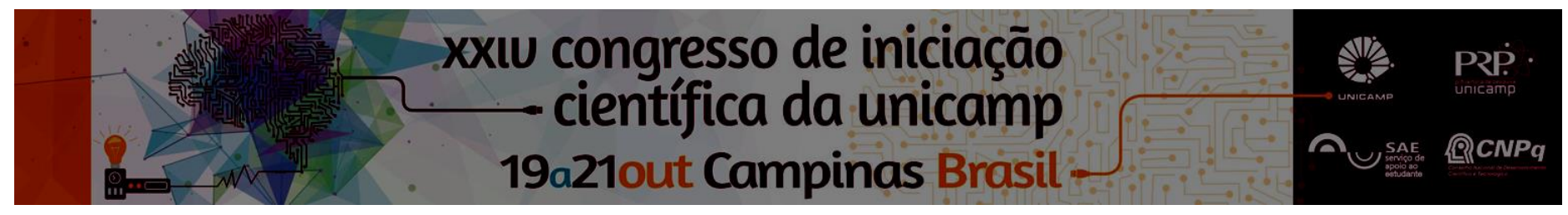

\title{
EFEITOS DO TECIDO EMISSOR DE INFRAVERMELHO LONGO NO DESEMPENHO DE CICLISTAS EM PROVA CONTRARRELÓGIO DE $4000 \mathrm{~m}$
}

\author{
Leonardo R. Motta*, Arthur F. Gáspari, João F. Barbieri, Rômulo C. Bertuzzi, Antônio C. de Moraes
}

\section{Resumo}

Os raios infravermelhos (IV) estão localizados entre as microondas e a luz visível no espectro eletromagnético e são subdivididos em IV Curto $(\lambda=0,7-1,4 \mu \mathrm{m})$, IV Medio $(\lambda=1,4-3 \mu \mathrm{m})$ e IV longo $(\lambda=4-100 \mu \mathrm{m})$. Métodos com irradiação por saunas ou lâmpadas emissoras de IV tem sido utilizados para o tratamento de lesões musculoesqueléticas. Neste contexto, vestimentas impregnadas com biocerâmica que irradia IV começaram a ser comercializadas como abordagens mais práticas e acessíveis. Embora os mecanismos de ação dos raios IV ainda sejam pouco compreendidos, sabemos que a sua emissão na pele humana pode desencadear vários efeitos fisiológicos, como aumento da microcirculação sanguínea, melhor eficiência da produção de energia e redução da fadiga. Entretanto, a literatura ainda carece de estudos que investiguem seus efeitos durante testes que simulem eventos esportivos.

\section{Palavras-chave:}

Infravermelho longo, Prova contrarrelógio, Desempenho aeróbio.

\section{Introdução}

O infravermelho (IV) longo vem sendo utilizado há muito tempo como terapia na área medica e fisioterápica. Entretanto, sua utilização como recurso ergogênico no ambiente esportivo é recente, e mais recente ainda quando é realizada por meio de tecidos impregnados com biocerâmica irradiante.

Os raios infravermelhos são absorvidos pelos tecidos corporais e se propagam pelo meio líquido celular (citoplasma), o que causa vibrações de estruturas e a ativação de processos fisiológicos, como a melhora do fluxo sanguíneo e a ativação de organelas e enzimas. Acredita-se que seus efeitos estejam relacionados ao aumento da biodisponibilidade de oxido nítrico e cálcio.

Estudos atuais apontam grande potencial ergogênico do IV no exercício físico. Entretanto, são raros os trabalhos que avaliaram os seus efeitos sobre provas esportivas, nas quais a distância a ser percorrida é conhecida e o desempenho é avaliado pelo tempo necessário para cumprir determinada tarefa. Estas provas são chamadas de Contrarrelógio e possuem como um dos principais determinantes a estratégia de pacing, que é a tática autosselecionada de distribuição da velocidade/potência que $\mathrm{o}$ atleta emprega durante $\mathrm{O}$ evento, com o objetivo tanto de concluir determinada tarefa no menor tempo possível, quanto de prevenir grandes prejuízos à homeostasia. Esses testes são caracterizados por ter grande sensibilidade na avaliação do desempenho, além de simularem com fidelidade um evento esportivo real.

\section{Objetivo}

O objetivo desse estudo será avaliar se o tecido emissor de IV longo causa alterações no desempenho e nas respostas fisiológicas de ciclistas treinados durante um Teste Contrarrelógio de 4000 metros.

\section{Métodos}

Os voluntários ( $~ 8$ ciclistas treinados, com idade entre 18 e 40 anos) serão submetidos a 5 sessões experimentais, utilizando bicicleta própria, compatível com o ciclossimulador (RacerMate ${ }^{\circledR}$, ComputrainerTM, Seattle,
USA). As duas primeiras sessões servirão para caracterização da amostra e a terceira para familiarização com o teste contrarrelógio de 4000 metros. As duas últimas sessões serão randomizadas e conduzidas no modelo cruzado e duplo cego. Os ciclistas utilizarão o tecido emissor de IV longo ou tecido placebo durante uma semana antes de cada teste contrarrelógio.

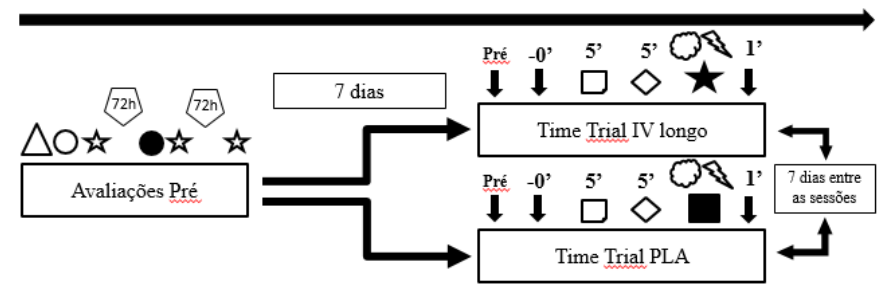
Familiarização com o ciclo simulador
- Avaliação Cardiorrespiratória
Familiarização com o Time Trial
$\triangle$ Registro de Medidas Antropométricas
72h Intervalo de 72 horas
\. Time Trial IV longo
Eletromiografia
Time Trial Placebo
$\square$ Aquecimento a $100 \mathrm{~W}$
$\diamond$ Repouso pré Time Trial
$\downarrow$ Coleta de Lactato
Análise de gases

\section{Hipótese}

Postulamos que a utilização do tecido emissor de IV longo irá melhorar o rendimento dos atletas durante o teste contrarrelógio, reduzindo o tempo total necessário para cobrir uma mesma distância. Essas alterações no desempenho poderão ser mensuradas por meio da ativação muscular, medida por eletromiografia de superfície nos músculos reto femoral, vasto lateral e vasto medial; concentração de lactato sanguíneo; consumo de oxigênio e produção de dióxido de carbono; contribuição dos sistemas energéticos; gasto energético; potência (W) e percepção subjetiva de esforço. 